\title{
ASSESSMENT OF THREE TECHNIQUES IN SURPASSING LEDGES IN CURVED GANALS
}

\section{Scarlatescu Sanziana Adina1, Gheorghiu Irina-Maria2, Mitran Loredana ${ }^{3}$, Mitran M.4, Temelcea Anca-Nicoleta5, Georgian Ene Liviu', Sfeatcu Ruxandra ${ }^{6}$, Perlea Paula'}

${ }^{1}$ Department of Endodontics, Faculty of Dental Medicine, UMF "Carol Davila" Bucharest

${ }^{2}$ Department of Restorative Odontotherapy, Faculty of Dental Medicine, UMF "Carol Davila" Bucharest

${ }^{3}$ Department of Otorhinolaryngology, Elias Hospital

${ }^{4}$ Department of Obstetrics and Gynecology, Faculty of Medicine, UMF "Carol Davila" Bucharest

${ }^{5}$ Department of Dental Technique, Faculty of Dental Medicine, UMF "Carol Davila" Bucharest

${ }^{6}$ Department of Oral Health Education, Faculty of Dental Medicine, UMF "Carol Davila" Bucharest

Sinziana Adina Scarlatescu

Faculty of Dental Medicine, "Carol Davila",

\begin{abstract}
The ledge formation is an iatrogenic accident that occurs in a curved canal due to the incorect application of the preparation techniques. The aim of this study was to find out which of the three well-known obturation techniques can surpass better an artificial created ledge. Matherials and methods: artificial ledge were created using Gates-Glidden drills no. 1 and 2 at $15 \mathrm{~mm}$ and no. 3 at $13 \mathrm{~mm}$ of the working lenght of fortyfour resin blocks. Thirty blocks that didn't allowed a \#10 file to surpass the ledge were accepted for study, divided into three equal groups and filled by lateral condensation, thermal compaction and continuous wave System $B$ technique. Results: System B resulted in the highest obturated area beyond the starting point of the ledge $(p<0,05)$, while lateral condensation showed the worst results. There were no differences between thermal compaction and lateral condensation in surpassing the deviation. Conclusion: within the limitation of this study, System B seems to be the the most appropriate techique when trying to surpass a ledge.
\end{abstract}

Keywords: ledge formation, root canal filling, root canal therapy

\section{Introduction}

Endodontic treatment is most of the time the last chance before extraction. Due to the diversity of root canal system, the endodontic treatment could be complicated and full of riscks. The ledge is an iatrogenic accident that occurs due to mismanagement of the apical third of the curved canal and is a platform created on the external wall of the curvature $(1,2)$.

The major causes of ledge formation are $(3,4,5)$ :

- inadequate acces cavity that doesn't allow straight line acces to the apical part of the canals
- excessive enlargement of the curvature using too-large instruments

- excessive use of rigid, stainless steel files in the apical part of curved canals

- inadequate irrigations and lubrication

- wrong working lenght determination

- packing dental debris in the apical part of the canal.

It will be very difficult to prepare the canal after the ledge formation because the patency is lost and the working lenght can no longer be negociated. Futhermore, the root canal filling could be compromised due to decreased working lenght and incomplete disinfection of root canal. All these factors lead to endodontic treatment 
failure.

In case of occurence, negociation with small files and bypassing the deviation should be attempted in order to regain the patency of the entire canal. In some cases, the amount of debris left in the uninstrumented apical part of the canal cannot permit to regain the patency and the correct shaping of the entire canal space. In this situation cleaning and shaping is completed at the new working lenght $(3,5)$.

The aim of this study was to compare the efficiency of three different obturation techniques to surpass the ledges artificial created in the curved apical part of resin blocks. The objectives were: 1) to create an artificial ledges in the starting point of the curvature;

2) to measure the distance the filling material was able to surpass the deviation; 3 ) to show using photos images the efficiency of these three techniques to fill and to surpass the ledges formed in curved canals.

\section{Materials and methods}

Forty-four endodontic resin blocks with 200 curvature degree and $18 \mathrm{~mm}$ working lenght were used for this study. The curved canals were negociated using \#10 flexofiles (Dentsply Sirona, Ballaigues, Switzerland) and preliminary enlarged till \#15 flexo files (Dentsply Sirona, Ballaigues, Switzerland). The ledge were prepared using Gates-Glidden (Dentsply Sirona as follows: drills no. 1 and 2 at $15 \mathrm{~mm}$ and drill no. 3 at $13 \mathrm{~mm}$ of the working lenght. Using a precurved \#10 an attempt was maid to surpass the ledge. Those resin blocks that allowed this passage were rejected and remained those were regaining the entire working lenght was impossible $(\mathrm{n}=30)$. After irrigation with $\mathrm{NaOCl}$ $2 \%$, the canals were dried with paper points \#50. The resin blocks were divided into 3 groups according to the filling techniques: thermal compaction technique, lateral condensation and countinuous wave System B technique. AH Plus (Dentsply Sirona) was used as a sealer in all experimental groups.

Group $1 \quad(n=10)$ was filled by lateral condensation. The gutta-percha master cone \#70 was inserted in the canal and with a red finger spreader the cone was condensed on the lateral wall of the canal. The same spreader was used to create space and to condense the accessory cones \#20 beside the master cone. The procedures was repetead until the insertion of new cones was not possible.

In group $2(n=10)$ the root canal filling has been performed by thermal compaction technique using gutta-condensers (DentsplySirona). A well-fitted gutta-percha master con \#70 (Dentsply-Sirona) was coated with sealer and put in the canal up to $15 \mathrm{~mm}$. A MacSpadden guttacondensor \#70 (Dentsply-Sirona) was introduced passively next to the master cone and, using a low-speed of $8000 \mathrm{rpm}$, it was driven forward up to $1 \mathrm{~mm}$ from the entire working lenght. The condensor was left for 1 second at that point and then removed on one side of the canal wall.

Group $3(\mathrm{n}=10)$ was filled using System B (SybronEndo). The master cone \#70 was coated with sealer and fitted in the canal up to $15 \mathrm{~mm}$. The heated plugger FM was introduced as could as possible near to the starting point of the ledge, kept in place for about 10 seconds and then removed from the canal with the rest of the cone. A cold plugger no.1 (P.Machtou, Dentsply-Sirona) was used for vertical compaction. Backfilling was performed by SybronEndo gun with gutta percha pellets heated to aproximately 2000 . The aria of gutta-percha that was able to surpass the starting point of the ledge was measured in all resin blocks and expressed in mm2. Data were statistically analized using ANOVA test, with 5\% significant level set and the photographs were taken with a photo-camera Nikon D5100.

\section{Results}

Resin blocks filled with System B showed the highest obturated area beyond the starting point of the ledge $(p<0,05)$ (table 1, fig. 1). Although lateral condensation showed the worst results in filling the area beyond the deviation, there were no differences between this techniques and thermal compaction ( $p>0,05$ ) (fig. 2, fig.3). 
Table 1. Mean obturated area beyond the ledge according to the filling techniques used in the experiment

\begin{tabular}{|l|c|c|c|}
\hline & $\begin{array}{c}\text { System B } \\
\text { (group 1) }\end{array}$ & $\begin{array}{c}\text { Lateral } \\
\text { condensation } \\
\text { (group 2) }\end{array}$ & $\begin{array}{c}\text { Thermal } \\
\text { compaction } \\
\text { (group 3) }\end{array}$ \\
\hline Mean (mm2) & 0.993 & 0.094 & 0.198 \\
\hline
\end{tabular}

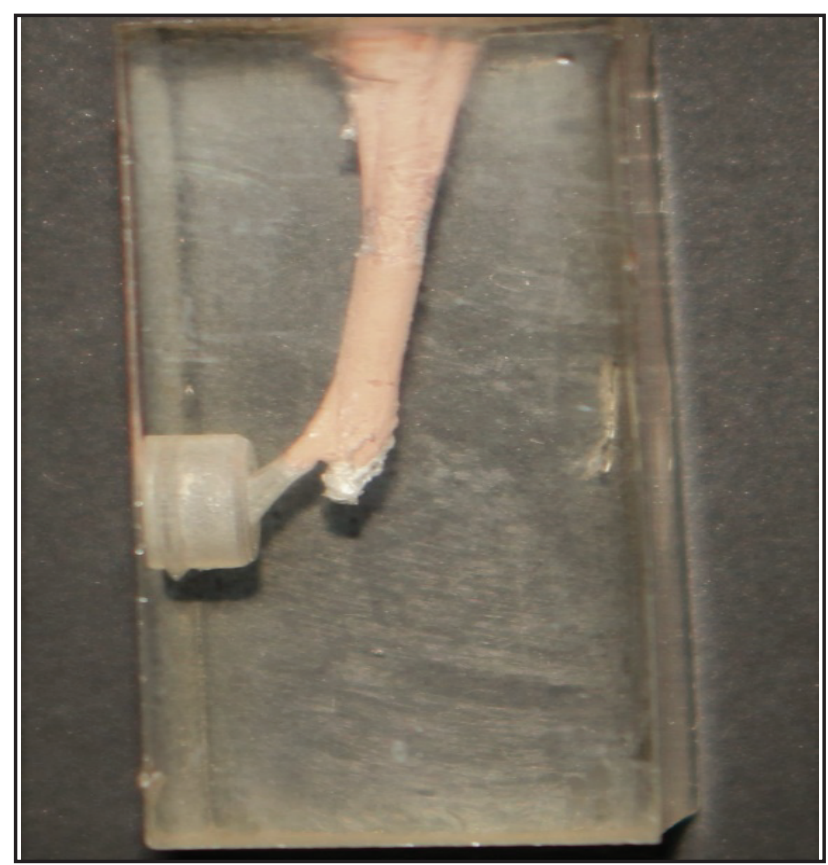

Fig. 1 resin blocks obturated by using System B

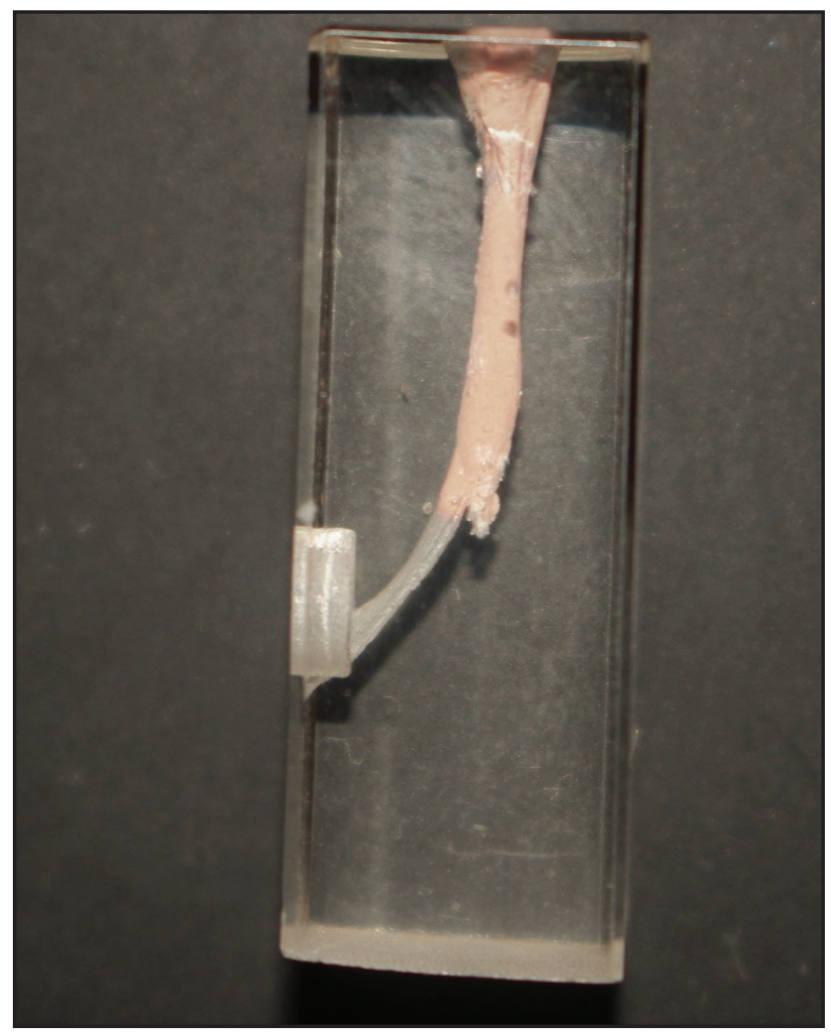

Fig. 2 resin blocks obturated with thermal compaction

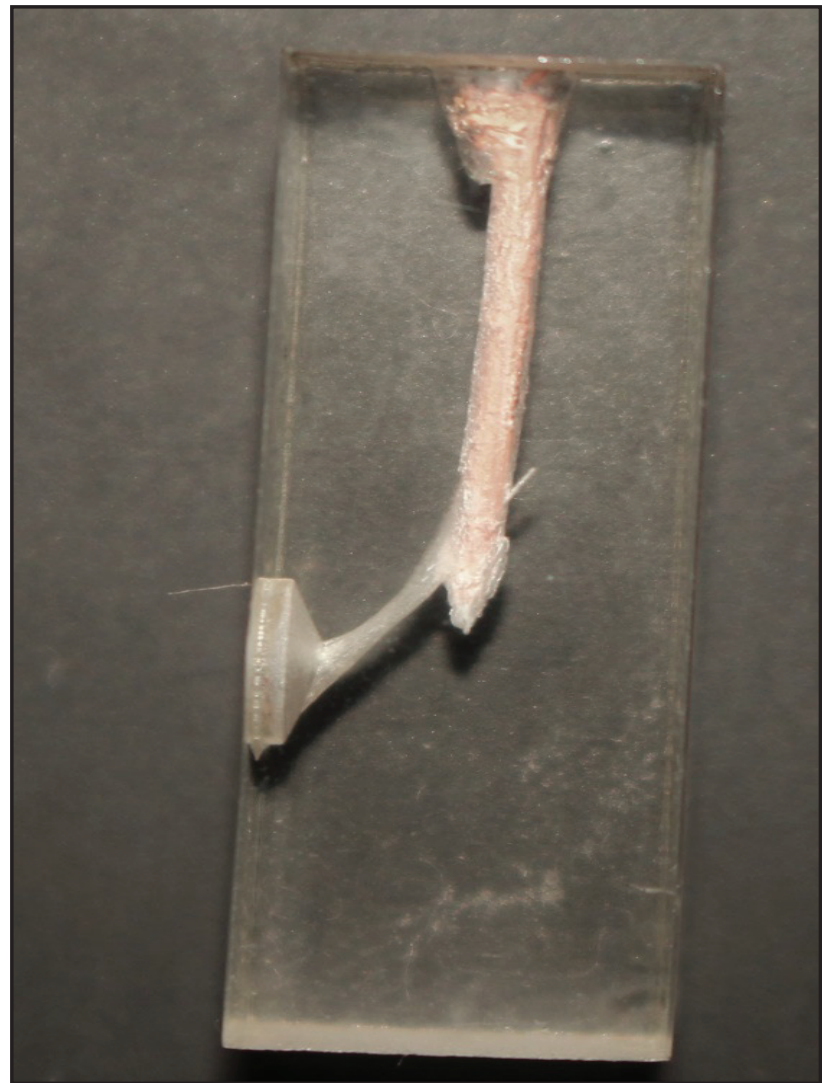

Fig. 3 resin blocks obturated with lateral condensation

\section{Discussion}

During the instrumentation, the maintenance of the original shape of root canal is a true challenge for most of the practitioners. The ledges are one of the worst iatrogenic errors that could appear during the curved canal instrumentation, because of the incorect use of endodontic instruments and files.

Regaining the patency of the root canal can be very challenging and cleaning and shaping more difficult to achieve. When a ledge occurs, it is mandatory to make a radiograph of the tooth with the instrument in place for providing additional information. Using a small steel file no.10, the practitioner should attempt to bypass the ledge with "watch-winding" motions, in order to help advance the instrument. (3). Also a "picking" motion is useful to feel the original canal space and then, with a reaming motion and up and down movement, to mantain the preparation of the canal space (5).

The acrylic endoblocks were frequently used in experimental studies, because of their good reproducibility as a model of a curved canal 
$(6,7)$.

This study revelead that lateral condensation showed the worst results in filling the area beyond the ledges because of the limited penetration until the ledge of the finger spreader and therefore the accessory cones were not able to enter beyond this area $(8,9,10)$.

The thermal compaction has shown to produce the best homogeneity of the filling root canal and a great overextension of filling materials $(11,12)$. However, despite the fact that gutta-percha was efficiently termoplasticized and mixed with the sealer by gutta-condensers it seems that this technique was limited in surpassing the ledge (13).

System B produced the highest obturated area beyond the ledge. This result can be explain by the great capability of plugger penetration into the depth of the obturation (14). Our results is similar with those who found that vertical condensation developed the most extrusions of sealer and gutta- percha in straight and curved canals $(12,13,15,16)$. Thus, this technique should be considered as an alternative in cases in which the entire working lenght is lost due to the ledge and it's impossible to regain the patency.

\section{Conclusion}

Within the limitation of this study, System B seems to be the the most appropriate techique when trying to surpass a ledge than thermal compaction and lateral condensation techniques.

\section{Acknowledgements}

For this article all the authors have equal contributions.

\section{References}

1. Castellucci A. Endodontics, vol. 1. Il Tridente, Firenze, 2007; p.244-252.

2. Iliescu A. Tratat de Endodontie, vol. 2, Ed. Medicala 2014, 593-594.

3. Ingle JI, Bakland LK, Baumgartner JC. Endodontics. 6th ed. BC Decker Inc, Hamilton, Ontario;2008; p.1122-1123.

4. Lumley P, Adams N, Tomson P. Practical Clinical Endodontics. Churchill Livingstone
Elsevier Edinburgh; 2006; p.35-37.

5. Torabinejad M, Lemon RR. Procedural Accidents. In: Torabinejad M, Walton RE, editors. Endodontics: Principles and Practice. 4th ed. Sauders Co. St. Louis; 2009; p.328330 .

6. Burroughs JR, Bergeron BE, Roberts MD, Hagan JL, Himel VT. Shaping ability of three nickel-titanium endodontic file systems in simulated S shaped root canals. J Endod. 2012; 38: 1618-21.

7. Kum K, Spangberg L, Cha BY, Young Y, Seung J, Chan-Young L. Shaping ability of three ProFile rotary instrumentation techniques in simulated resin root canals. J Endod 2000;26 (12):719-723.

8. Weis MV, Parashos P, Messer HH. Effect of obturation technique on sealer cement thickness and dentinal tubule penetration. Int Endod J 2004; 37:653-663.

9. Monticelli F, Sword J, Martin RL, Schuster GS, Weller RN, Ferrari M, Pashley DH, Tay FR. Sealing properties of two contemporary single-cone obturation systems. Int Endod J 2007; 40:374-385.

10. Somma F, Cretella G, Carotenuto M, Pecci R, Bedini R, De Biasi M, Angerame D. Quality of thermoplasticized and single point root fillings assessed by micro-computed tomography. Int Endod J 2011;44:362-369.

11. Scărlătescu SA, Iliescu A, Didilescu AC, Ştefan DS, Iliescu AlA. A comparative study of the root canal fillings based on warm gutta-percha condensation techniques. Int $\mathrm{J}$ of Romanian Dent 2012a;2:102-106.

12. Scărlătescu SA, Iliescu A, Didilescu AC, Ştefan DS, Iliescu AlA. The assessment of four methods of the gutta-percha root canal filling investigated by tooth-clearing technique. Medicine in evolution 2012b; 18:95-101.

13. Carneiro Leão Gabardo M, José da Silva W, Machado Gonçalves L, Deonízio MDA: Effectiveness of different obturation techniques in surpassing the ledge formed in simulated curved canals. Braz J Oral Sci 2013;12 (2): 138-142.

14. Zhang W, Suguro H, Kobayashi Y, Tsurumachi T, Ogiso B. Effect of canal taper and plugger size on warm gutta-percha 
obturation of lateral depressions. J Oral Sci. 2011; 53: 219-24.

15. Guess GM, Edwards KR, Yang ML, Iqbal MK, Kim S. Analysis of continuous-wave obturation using a single-cone and hybrid technique. J Endod. 2003; 29: 509-12.

16. Jung IY, Lee SB, Kim ES, Lee CY, Lee SJ. Effect of different temperatures and penetration depths of a System B plugger in the filling of artificially created oval canals. Oral Surg Oral Med Oral Pathol Oral Radiol Endod. 2003; 96: 453-7. 